\title{
The Application of Computer Management System in Physical Education Teaching
}

\author{
Liying Chen ${ }^{1}$ \\ ${ }^{1}$ Jimei University, Fujian, China, 361021
}

\begin{abstract}
School physical education(PE) is an indispensable part of school education, which plays an important and irreplaceable role in training builders of socialist cause with all-round development of morality, intelligence and sports. Sports network teaching management greatly improves the efficiency and efficiency of school sports teaching, which is a great change of the traditional mode., it provides a solid foundation for the establishment of Sports Network Teaching in Colleges and universities(CAU). This paper mainly studies the application of computer management system(CMS) in physical education teaching(PET). This paper studies and analyzes the method of university teaching computer management resources integration, studies the architecture of sports teaching CMS from four aspects of computing resources, storage resources, backup resources and network system, and uses ant colony algorithm to design and use sports teaching CMS. This paper also uses charts to analyze students' attitude towards the use of CMS in PET, and the proportion of CMS in PET. The experimental results show that in the CMS of PET, the computing resources account for $38.33 \%$, the storage resources account for $31.76 \%$, the backup resources account for $14.62 \%$, and the network system account for $15.29 \%$.
\end{abstract}

\section{Introduction}

In recent years, with the rapid development of computer technology and network communication technology, the combination of the two has been gradually introduced into the teaching field, promoting the reform of traditional education [1-2]. In contemporary China, people's living income is constantly improving. Even in remote rural areas, the popularity of computers has a certain scale. The continuous improvement and low cost of national communication network infrastructure make it possible for schools to carry out network teaching [3-4]. With the support and help of national policies and funds, CAU across the country have established their own teaching network. Some CAU have realized online teaching of main courses, and many distance education platforms have even been established among schools, through which teaching resources have been fully utilized [5-6]. Due to the higher requirements of teacher-student interaction and practicality in PET, it is more difficult to realize PE network teaching than general teaching subjects, and the status of PE subjects in the traditional education of domestic CAU is not high, so it is difficult to attract the attention of teachers and students [7-8]. Therefore, the development of sports network teaching, the use of sports teaching CMS is imminent [9-10].

In the research on the application of CMS in PE, many scholars at home and abroad have made some achievements. Juhe $\mathrm{W}$ believes that another deficiency of the current sports network teaching is that the sports teaching resources are limited and the excellent resources are less. We must speed up the construction of sports excellent courses and improve the quality of sports network teaching resources [11]. Da Wei $\mathrm{C}$ pointed out that in the network teaching, many teachers lack the concept of network teaching, and the construction of network teaching staff needs to be strengthened, so as to speed up the transformation of teachers' role and help them get rid of the traditional teaching as soon as possible. Mastering the methods and methods of network teaching is one of the key tasks to promote network teaching [12].

This paper mainly studies the application of CMS in PET. This paper studies and analyzes the methods of the integration of teaching computer management resources in CAU. We should realize the reasonable allocation of resources, strengthen the unified management, and reduce the energy cost. In this way, we can carry out the resource allocation of college PE management system and improve the quality of PE. This paper also studies the architecture of the CMS of PET from the four aspects of computing resources, storage resources, backup resources and network system, and designs the CMS of PET by using ant colony algorithm. This paper also uses charts to analyze students' attitude towards the use of CMS in PET, and the proportion of CMS in PET. 


\section{The CMS of PE}

\subsection{Integration Method of Teaching Computer Management Resources in CAU}

(1) Realize the rational allocation of resources

Because of the particularity of the computer network service platform, the requirement of the network environment is relatively low, and there is no need to invest a large cost in this aspect, so it has the characteristics of strong adaptability. In the process of applying the educational administration management system in CAU, we need to rely on a multi style environment and have a certain cross platform ability, so as to speed up the construction of intelligent teaching campus environment, make greater contributions to promote the development of CAU, and meet the development needs of the times. In addition, the management system should provide a variety of services according to the different needs of users, make efficient use of resources, and truly achieve the sharing and interaction of data and information. There are many factors that lead to cloud platform service anomaly, one of which is the reference peak to configure resources, which makes the effectiveness of the system is not high. This requires that the management system must change the traditional management mode, adjust the allocation of resources and infrastructure reasonably and effectively, improve the use efficiency of network resources, and ensure the resource application to achieve a dynamic balance. For the university management system based on cloud platform, in the configuration of hardware equipment, we should implement efficient management and maintenance work from the perspective of actual needs, ensure that the system can operate continuously and stably, and provide a solid guarantee for the improvement of the efficiency of university sports educational administration. At the same time, it can also reduce the amount of labor of the management staff, and the goal of scientific management can be achieved by simple operation of the staff.

(2) Strengthen unified management

To build a computer-based teaching platform in CAU, it is necessary to realize the consistent management and maintenance of the network operation environment. While minimizing the cost, it is also necessary to make a dynamic and reasonable allocation of internal resources, improve the management level and ability, so that a variety of data and information can be processed and stored uniformly, and the management is more standardized and standardized, further improve the control performance of the management system.

(3) Reduce energy costs

The management service platform must maximize the use of resources, with its high-quality computing function to reduce costs, real-time supervision and management of energy input, on the one hand, it can make the management staff more comprehensive analysis of the system application, on the other hand, it also speeds up the pace of realizing green it in the university sports educational administration management system.
Combined with the above needs, the computer platform plays a key role in realizing the sustainable development of educational administration in CAU. It can reduce the cost of energy investment, and is also the top priority of implementing the scientific outlook on development. Under the guidance of Internet thought, the computerbased university sports educational administration management system plays the advantages of advanced network cloud technology, which can improve the quality of university education, create favorable opportunities for the further development of universities, ensure the efficient use of various resources, further develop the advantages of universities and make up for its shortcomings, it is of great significance to improve the teaching efficiency.

\subsection{Architecture of CMS for PET}

\section{(1) Computing resources}

The CMS of PET is mainly composed of application and data servers, which plays an important role in the whole management system. There are six servers for auxiliary operation, and four servers with computing resources, which mainly play the role of supporting the protection of data for backup.

(2) Storage resources

A very important part of the CMS of PET is the storage resources. The CMS uses its storage resources, occupies a high position in calculating data and protecting data. It can process and screen effective data, carry out data migration and backup, improve the quality of PET, operate PET resources, and improve the utilization rate of resources. To a certain extent, storage resources can ensure the real availability of CMS information. In case of abnormal situation and damage, the data can be recovered to ensure the reasonable operation of the management system.

(3) Backup resources

The backup device in the computer platform has a large capacity, and it does not need to occupy a large area in the process of operation, so it can realize the backup storage of data. The backup device has the functions of backup and storage, realizes the combination and unification of the two, and reduces the investment in the teaching platform of College PE Management Based on computer. In terms of backup resources, the computer platform can provide users with a relatively simple and easy to operate interface. If the user's operation is not correct, it can also respond in time. Under the effect of the efficient performance of the backup equipment, it can store and keep a variety of information of university sports educational administration management, which can fully meet the actual needs of university management, on this basis, it can reduce the waste of energy, realize intelligent and automatic adjustment and operation, and greatly improve the use efficiency of network resources and power.

(4) Network system

It is compatible with the existing network system. The network system of college PE administration management system based on cloud platform, in the design stage, must carefully check and analyze the hardware equipment 
applied to ensure that the quality of equipment meets the requirements, at the same time, it can guarantee the reliability of data information, so that the management staff can manage more easily and quickly, and meet the less needs of users, To achieve the goal of personalized expansion, the application efficiency is the best.

\subsection{Ant Colony Algorithm Management System Design}

Ant colony algorithm is mainly used to find the optimal configuration path in the image by searching and finding the path. The main ant issues tasks to each ant before they travel. After they travel, they record their itinerary and write each location of the management task to match. At the end of the first cycle, they compare the location of each ant's temporary task and find out the best management method through analysis. In the process of traveling around, ants will exchange information, and there will be the same information at the beginning, but with the optimization of ants, the amount of path information will gradually increase. In the management system, ant colony algorithm is used to find the best matching arrangement, and the specific formula is as follows:

$$
\begin{array}{r}
T_{i j}(t+n)=(1-p) * T_{i j}(t)+\Delta T_{i j}(t) \\
\Delta T_{i j}(t)=\sum_{k-1}^{m} \Delta T_{i j}^{k}(t)
\end{array}
$$

All ants go from one node in LCT to another node in GPR in bipartite model. When all ants return to LCT, they will go on a new round of logical tour activities, and so on, until all the management activities in LCT are configured.

\section{Experimental Study}

\subsection{Subjects}

The main content of this paper is the analysis of the application of CMS in PE. In order to understand the management of PET in CAU, this paper sent a questionnaire to 200 college students in the form of questionnaire to understand their attitudes towards the use of CMS in PET.

\subsection{Experimental Process Steps}

This paper mainly studies the application of CMS in PET. This paper studies and analyzes the methods of the integration of teaching computer management resources in CAU. We should realize the reasonable allocation of resources, strengthen the unified management, and reduce the energy cost. In this way, we can carry out the resource allocation of college PE management system and improve the quality of PE. This paper also studies the architecture of the CMS of PET from the four aspects of computing resources, storage resources, backup resources and network system, and designs the CMS of PET by using ant colony algorithm. This paper also uses charts to analyze students' attitude towards the use of CMS in PET, and the proportion of CMS in PET.

\section{Experimental Research and Analysis of CMS in PE}

\subsection{The Attitude Towards the Use of CMS in PE}

This paper makes a comprehensive investigation on the management system of college PE, because the management of PE is also an important part of the management of college education, so this paper studies the management of college PE. In this paper, in the form of questionnaire, a questionnaire survey was conducted on college students. A total of 200 questionnaires were collected and sorted out. Through the questionnaire survey, students' attitude towards the use of CMS in PET was understood. The results are shown in Table 1.

Table 1. Attitude towards the use of CMS in PET

\begin{tabular}{|c|c|c|c|}
\hline & support & indifferent & not support \\
\hline number & 139 & 48 & 13 \\
\hline proportion & $69.5 \%$ & $24 \%$ & $6.5 \%$ \\
\hline
\end{tabular}

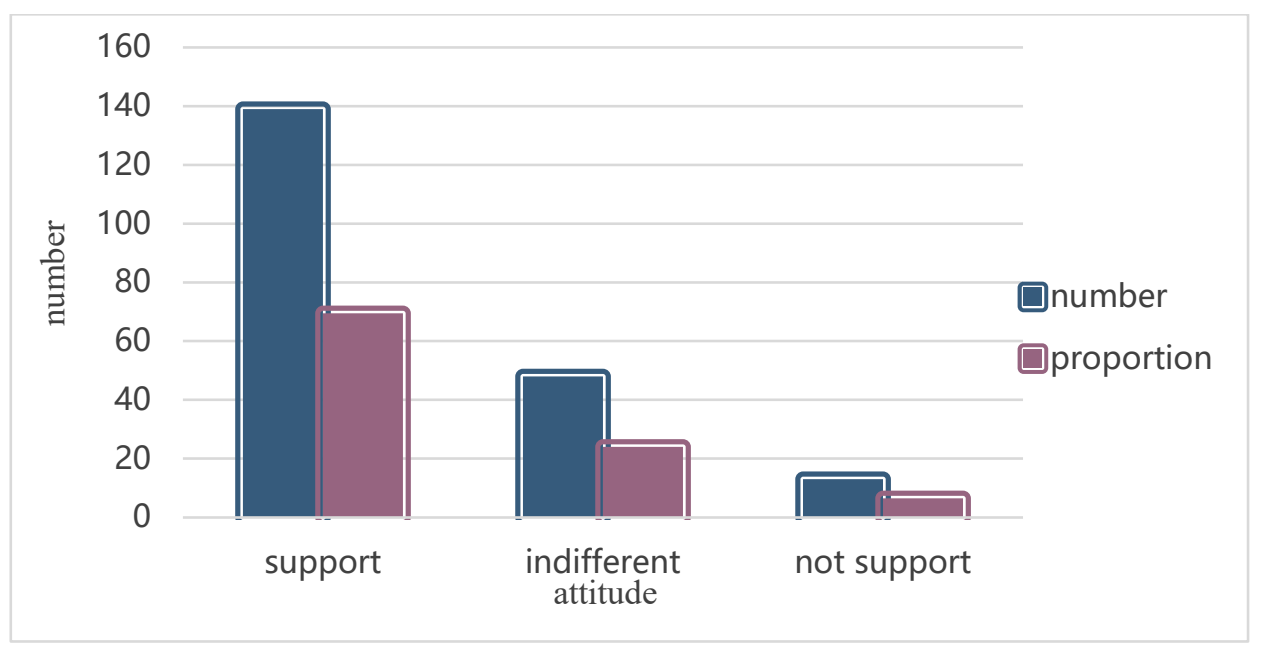

Figure 1. Attitude towards the use of CMS in PET 
It can be seen from Figure 1 that $69.5 \%$ of the students support the use of the CMS in PE, $24 \%$ of the students have a indifferent attitude about whether to use the CMS in $\mathrm{PE}$, and $6.5 \%$ of the students refuse to use the CMS in PE.

\subsection{The Proportion of CMS in PET}

In this paper, the proportion of CMS in PET is studied. Through the background data, the proportion of computing resources, storage resources, backup resources and network system in the CMS of PET is studied. The data results are shown in Table 2 .

Table 2. The proportion of CMS in PET

\begin{tabular}{|c|c|c|c|c|}
\hline & $\begin{array}{c}\text { computing } \\
\text { resource }\end{array}$ & $\begin{array}{c}\text { Storage } \\
\text { resources }\end{array}$ & $\begin{array}{c}\text { Backup } \\
\text { resources }\end{array}$ & $\begin{array}{c}\text { Network } \\
\text { system }\end{array}$ \\
\hline $\begin{array}{c}\text { proport } \\
\text { ion }\end{array}$ & $38.33 \%$ & $31.76 \%$ & $14.62 \%$ & $15.29 \%$ \\
\hline
\end{tabular}

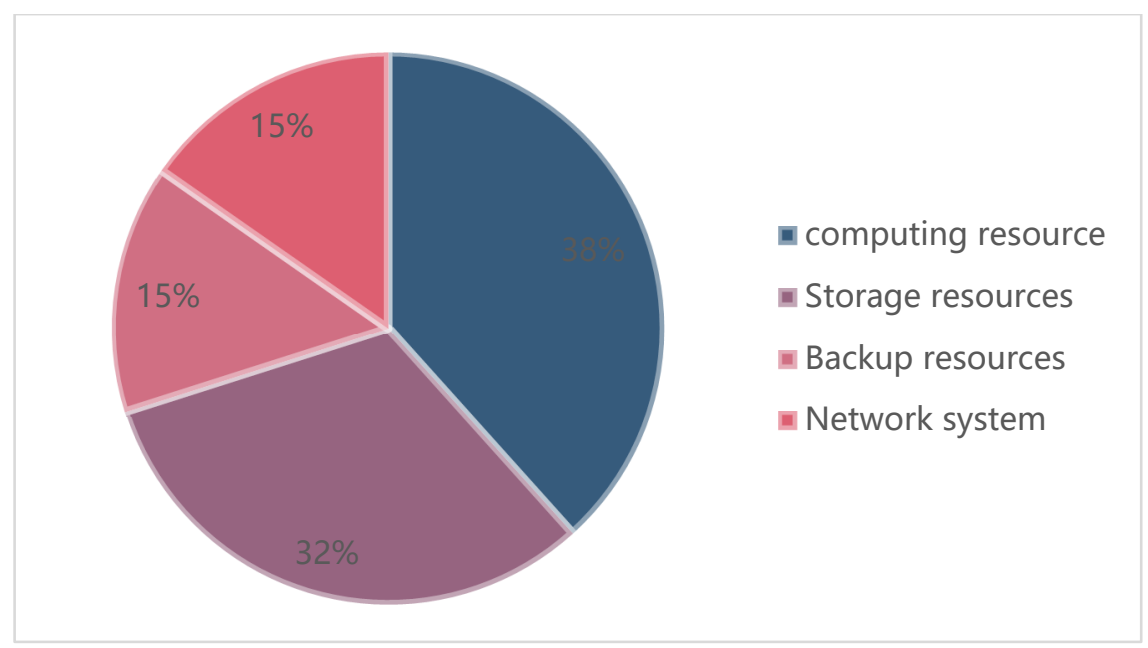

Figure 2. The proportion of CMS in PET

As can be seen from Figure 2, in the CMS of PET, the computing resources account for $38.33 \%$, the storage resources account for $31.76 \%$, the backup resources account for $14.62 \%$, and the network system account for $15.29 \%$.

\section{Conclusions}

This paper studies the method of university teaching computer management resources integration, from the four aspects of computing resources, storage resources, backup resources and network system to study the architecture of sports teaching CMS, through the use of ant colony algorithm to design and use sports teaching CMS. This paper puts forward the analysis of the application of CMS in PET, aiming at building a suitable teaching management system for PET, ensuring the normal operation of the system continuously and stably, and providing a solid guarantee for the improvement of the efficiency of college PE administration.

\section{References}

1. Viciana $\mathrm{J}$, Mayorga-Vega D . Innovative teaching units applied to physical education - Changing the curriculum management for authentic outcomes[J]. Kinesiology, 2016, 48(1):142-152.

2. Chen W, Mason S, Hypnar A, et al. Physical Education Teaching Study 3[J]. Journal of Sports Science \& Medicine, 2016, 15(2):335.

3. Kim, Bokyeon, Choi, et al. Differences in High-
Commitment Human Resource Management and Service Quality Perceived by Regular and NonRegular Workers in Commercial Sports Facilities[J]. The Korean Journal of Physical Education, 2017, 56(3):283-303.

4. Ridley D S, Hurwitz S, Hackett M, et al. Comparing PDS and campus-based preservice teacher preparation: is PDS-based preparation really better?(professional development school )[J]. Journal of Teacher Education, 2016, 56(1):46-56.

5. Li H, Zhang H, Zhao Y . Design of Computer-aided Teaching Network Management System for College Physical Education[J]. Computer-Aided Design and Applications, 2021, 18(S4):152-162.

6. Xia T . Based on Big Datacollege Physical Education Teaching Evaluation System Research[J]. Journal of Physics Conference Series, 2021, 1744(3):032010.

7. Xie $X$. An optimization method for physical education teaching evaluation system analysis and intelligent assessment system design[J]. Boletin Tecnico/Technical Bulletin, 2017, 55(16):62-67.

8. Peng Q . Optimization of Physical Education and Teaching Quality Management based on BP Neural Network[J]. Boletin Tecnico/Technical Bulletin, 2017, 55(7):643-649.

9. Lin W . A Study on the Management of Online Teaching Resources for Track and Field Courses in Colleges of Physical Education.[J]. International Journal of Simulation: Systems, 2016, 17(48):8.18.10 . 
10. Xu H, Zhang X . Construction and implementation of physical education teaching evaluation system based on stochastic simulation algorithm[J]. Revista de la Facultad de Ingenieria, 2017, 32(15):632-636.

11. Juhe W, Zhibin W . Research on college physical education teaching mode based on multimedia teaching system[J]. Agro Food Industry Hi Tech, 2017, 28(1):353-356.

12. Da-Wei C, Chao L, Shun W, et al. Research and application of multimedia digital platform in the teaching of college physical education course[J]. Journal of Intelligent and Fuzzy Systems, 2018, 34(2):893-901. 